\title{
O que dizem os professores das oficinas curriculares de escolas estaduais de tempo integral de Campinas
}

\author{
Regina Carvalho Calvo de Faveri ${ }^{1}$ \\ Vera Lúcia de Carvalho Machado ${ }^{2}$
}

\section{Resumo}

Neste trabalho, analisam-se as percepções dos professores das oficinas curriculares de Escolas de Tempo Integral (ETI) em Campinas, São Paulo, no que diz respeito à qualidade educativa. O Projeto ETI foi implementado na rede estadual em 2006, por iniciativa do governo do estado e contou com a publicação das Diretrizes da Escola de Tempo Integral (DETIs), que nortearam a implantação do modelo em unidades que atendiam em tempo parcial e passaram a ter jornada ampliada. A compreensão dos professores sobre a forma de organização das oficinas foi observada como aspecto preponderante no processo de implantação da ETI e foi analisada a partir de pesquisa qualitativa, realizada no ano de $2011 \mathrm{em}$ duas escolas estaduais de tempo integral, por meio de entrevistas semiestruturadas e análise de documentos. Os resultados apontaram para o fato de as percepções desses profissionais sobre a formação docente e a integração da equipe estarem diretamente relacionadas à qualidade educativa.

Palavras-Chave: escola de tempo integral; ampliação de jornada; política educacional; oficinas curriculares; qualidade educativa.

1 Mestre em Educação pela Pontifícia Universidade Católica de Campinas (PUC-Campinas). Professora na PUC-Campinas e na Anhanguera, Brasil. reginafaveri@yahoo.com.br

2 Doutora em Educação. pela Universidade Estadual de Campinas (Unicamp). Professora na PUCCampinas, Brasil. veris@puc-campinas.edu.br 


\title{
The perception of the teachers participating in curricular workshops at full-time state schools in Campinas
}

\begin{abstract}
The presented paper analyzes the perception of the teachers involved in workshops on Full-Time schools in Campinas, State of São Paulo, about educational quality. The Full-Time Schools Project was implemented in 2006 by the state government on state educational network of São Paulo. This process counted on the official documents publication such as the Full-Time School Guidelines, which guided the implantation of this model in partial-time schools that now have extended school day hours. The comprehension from the teachers perspective about the organization of the workshops was seen as a prevailing aspect in the process of implementing this educational model and it was analyzed based in a qualitative research, which happened in the year of 2011 in two full-time schools, using semistructured interviews and analysis of the documentation. The results pointed to the fact that the perceptions of these professionals on formation of teachers and integration of the team are directly connected to the educational quality.
\end{abstract}

Keywords: full-time schools; extension of school day; educational policy; curriculum workshop; education quality.

\section{A Escola de Tempo Integral em São Paulo: perspectivas para a qualidade educativa}

O Projeto Escola de Tempo Integral (ETI) em São Paulo foi instituído no ano de 2006, em decorrência da Resolução $n^{\circ} 89$, de 9 de dezembro de 2005. De acordo com o documento, pretendia-se prolongar o tempo dos alunos de Ensino Fundamental na escola pública estadual e ampliar as possibilidades de aprendizagem, com o enriquecimento do currículo, exploração de temas transversais e vivência de situações que favorecessem o aprimoramento pessoal, social e cultural.

Assim, escolas estaduais passaram a atender seus alunos em regime 
de tempo integral, com uma mudança na jornada de cinco para nove horas diárias. A resolução estabeleceu critérios para adesão das escolas ao programa, priorizando as unidades inseridas em regiões de baixo Índice de Desenvolvimento Humano (IDH). A gama de atividades das ETI manteve disciplinas do currículo regular, incluindo oficinas voltadas para a orientação de estudos; atividades artísticas e culturais; atividades desportivas e de integração social e de enriquecimento curricular.

$\mathrm{O}$ artigo $6^{\circ}$ determinou que à Coordenadoria de Estudos e Normas Pedagógicas (CENP), órgão ligado à Secretaria de Educação do Estado de São Paulo (SEESP), caberia a elaboração de Diretrizes Curriculares para as Escolas de Tempo Integral (DETIs).

As DETIs basearam-se em orientações gerais e sugestões para o planejamento, organização e avaliação das oficinas curriculares. $\mathrm{O}$ documento salientou a necessidade de aprofundamentos que transcendessem a dimensão quantitativa e nos permitiu reflexões acerca da relação quantidade-qualidade educacional a partir da implantação de escolas de jornada ampliada. Nessa perspectiva, o tempo pode proporcionar ao aluno possibilidades de aprofundamento de conhecimentos e vivências novas por meio de atividades artísticas e esportivas.

A existência das ETIs em Campinas, interior do estado, representa um caso particular, devido à ínfima quantidade dessas escolas no universo das escolas públicas e da peculiaridade de atendimento, mormente no que concerne à jornada diária. Conforme dados da SEESP, do total de 5.300 escolas estaduais em São Paulo, 313 são unidades de tempo integral, das quais seis estão em Campinas. Desenvolvemos o trabalho de campo em duas das três unidades que atendem alunos dos anos iniciais, denominadas A e B, respectivamente. Nossa intenção foi contemplar uma unidade de cada Diretoria de Ensino (DE), com o propósito de abarcar as duas regiões administrativas (leste e oeste), às quais pertencem todas as unidades escolares estaduais.

De acordo com o Plano de Gestão (PG) da unidade, a escola A foi criada em 1979 e tem uma média de 250 alunos classificados em nove turmas. Os 
alunos, em geral, são moradores da localidade, mas a escola é procurada por famílias de outros bairros vizinhos por oferecer atendimento em período integral. Destacou-se o fato de a comunidade necessitar de uma ETI, impedindo que as crianças fiquem na rua aleatoriamente, tornandose vulneráveis a todo tipo de risco. O documento ressaltou que parte dos alunos tem condições de vida consideradas satisfatórias enquanto que outros têm extremas dificuldades financeiras e sociais.

Em relação à estrutura física, a construção é bem projetada. A escola A ocupa um quarteirão e conta com dois pavimentos: no piso inferior, encontra-se a parte administrativa, sanitários, duas salas de primeiros anos, cozinha para os funcionários; sala de professores; ampla biblioteca e rampa de acesso ao pátio coberto. O pátio (espécie de subsolo) tem um salão com mesas e cozinha, além de saletas para atendimento pedagógico ou projetos e almoxarifado. Na parte externa, há quadra coberta, um pequeno parque, uma casa destinada à zeladoria e estacionamento. No piso superior, há mais oito salas de aula e um laboratório de informática amplo com dezesseis computadores. O mobiliário aparenta bom estado de conservação.

As aulas regulares concentram-se no período da manhã e à tarde ocorrem as oficinas curriculares previstas pelas DETIs, como hora da leitura, saúde e qualidade de vida, informática, atividades esportivas e motoras, linguagens artísticas, experiências matemáticas, inglês, orientação para estudo e pesquisa, teatro, artes visuais, música, dança. Assim, as crianças passam o dia todo na própria unidade. O documento apresentou a concepção pedagógica da ETI, detalhando os objetivos e metas, conteúdos, ações, estratégias avaliativas, resultados em avaliações externas. A ênfase no aprender a aprender, aprender a ser, aprender a conhecer e aprender a conviver, como pilares educacionais, nos permitiu compreender a perspectiva educacional, voltada ao desenvolvimento de habilidades e competências, em consonância com as DETIs. Ainda de acordo com o documento, o "sonho" da Escola A seria possibilitar autonomia, garantindo pluralismo de ideias e padrão de qualidade de ensino por meio do planejamento coletivo. 
A nosso ver, a citação exprimiu a concepção de ensino-aprendizagem valorizada:

A escola de hoje tem o objetivo de proporcionar aos alunos a aquisição dos conhecimentos básicos que constituem o patrimônio histórico, científico e cultural da humanidade, o pleno desenvolvimento de suas capacidades físicas, intelectuais e relacionais, bem como a inserção dos mesmos à sociedade, com competências que lhe permitam atender às demandas contemporâneas, por novas aprendizagens e atualizações permanentes. E para isso, a escola necessita revisar e redefinir papeis até agora inexistentes, a fim de adequar-se às novas exigências sociais, transformando a educação formal em um dos instrumentos do desenvolvimento individual, social e econômico. (p. 14)

O documento apontou para uma atuação docente pautada na reflexão sobre as necessidades de aprendizagem dos educandos, com vistas à qualidade educativa, a partir dos resultados alcançados e a importância do trabalho coletivo, pois

Um novo papel do professor decorre da necessidade, cada vez maior e mais urgente, de um serviço especializado que garanta certos parâmetros bem definidos no processo ensino-aprendizagem que se realiza na escola. Desta forma, o professor precisa ter clareza de promover a reflexão da sua equipe sobre os resultados alcançados com suas práticas, sobre as necessidades de aprendizagem dos alunos e, ainda, a importância do trabalho coletivo e a necessidade de se fazer cumprir o compromisso efetivo com a qualidade. (p. 14)

A referida proposta salientou seu embasamento em seis princípios definidos para todas as escolas estaduais: a escola como ambiente de aprendizagem, a compreensão do currículo como espaço de cultura, o eixo no desenvolvimento de competências, o foco nas competências leitora e escritora, a articulação das competências para aprendizagem e a contextualização do ensino no mundo do trabalho. Conforme mencionado no PG, a proposta pedagógica da Escola A procurou manter consonância com as demais unidades estaduais de ensino estaduais.

A escola B foi criada em 1978 e está situada em um bairro com boa infraestrutura. O prédio conta com dois pavilhões (térreos) de salas de aula separados por pequena escada de acesso. $\mathrm{O}$ maior tem sete salas 
e um laboratório de informática; o outro tem três salas. Existem duas quadras: uma mais antiga, que necessita de manutenção, e outra nova, coberta e cercada. A unidade conta com um refeitório amplo coberto, onde há uma cozinha com balcão de serviço, bebedouro e sanitários para os alunos. Na parte externa, foi construído um espaço utilizado para contação de histórias e outras atividades. Há também uma casinha de boneca plástica em área delimitada por cerca.

A composição do público da escola B é bastante heterogênea. Constitui-se de alunos de vários outros bairros da região. O PG informou que $10 \%$ dos alunos são de baixo poder aquisitivo e têm pouca assistência familiar, além de residirem em condições precárias.

Foram destacados no documento os quatro pilares educacionais que embasaram a educação pública da rede estadual de São Paulo no período: aprender a aprender, aprender a ser, aprender a conhecer e aprender a conviver. De acordo com o PG, a Escola B tomou como bases do trabalho pedagógico o desenvolvimento da competência leitora e escritora e do raciocínio lógico, a formação de valores imprescindíveis ao exercício da cidadania, a ética, a adaptação às evoluções do mundo, o equilíbrio emocional, a cultura da paz, a sensibilidade e a capacidade estética, o acesso às informações, com foco na ascensão social e melhores condições de vida. O PG tomou como meta o desenvolvimento físico, moral, mental, espiritual e social, considerando-se os princípios de liberdade e dignidade.

A pesquisa teve como objeto de investigação a qualidade educativa das oficinas curriculares, na ótica dos profissionais. O trabalho de campo, realizado no segundo semestre de 2011, contribuiu para a identificação e análise da compreensão dos sujeitos atuantes nas oficinas curriculares sobre o seu modo de organização.

\section{A questão da qualidade no discurso dos professores das oficinas curriculares: um estudo de caso}

As entrevistas semiestruturadas foram realizadas com dez sujeitos das duas ETIs do município de Campinas, sendo cinco de cada escola, 
denominados: sujeito 1, sujeito 2, sujeito 3 e, assim, sucessivamente. Elaboramos um roteiro prévio com onze questões a serem respondidas por professores das oficinas curriculares. Destacamos que o roteiro permitiu identificar aspectos que se configuraram como categorias analíticas. Dos dez sujeitos entrevistados, todos eram do sexo feminino e possuíam um tempo superior a cinco anos de docência, vide Quadro 1:

Quadro 1 - Tempo de Atuação no Magistério

\begin{tabular}{cc}
\hline Tempo de Magistério & Quantidade de Profissionais \\
\hline Entre 5 e 10 anos & 3 \\
Entre 10 e 15 anos & 2 \\
Mais de 15 anos & 4 \\
Mais de 20 anos & 1 \\
Total & $\mathbf{1 0}$ \\
\hline
\end{tabular}

Fonte: Elaborado pelas autoras com base nos dados da pesquisa.

O processo de transcrição foi de extrema relevância para as análises posteriores. Esse procedimento propiciou um novo olhar sobre os resultados das entrevistas. Fizemos então uma categorização desses textos em relação aos aspectos evidenciados. Houve recorrência de vários desses aspectos, o que consideramos em nossas análises. As análises foram realizadas a partir de categorias evidenciadas nos textos resultantes das entrevistas em relação à qualidade educativa das oficinas curriculares. Consideramos a recorrência presentes nos relatos.

Ludke e André (1986) afirmaram que as entrevistas, como instrumento de pesquisa, se diferenciam de outros procedimentos como observação e questionários por assumirem caráter de interação entre pesquisador e pesquisado. Destacamos que, neste artigo, utilizamos trechos dos relatos de alguns dos dez sujeitos entrevistados.

Vimos que $60 \%$ dos professores das oficinas obtiveram formação em Pedagogia e a totalidade concluiu curso de licenciatura em cursos diretamente ligados à Educação, de acordo com o Quadro 2, a seguir. 
Quadro 2 - Professores das Escolas A e B

\begin{tabular}{|c|c|}
\hline Sujeito & Formação \\
\hline 1 & $\begin{array}{c}\text { Graduação em Pedagogia com curso complementar na área da } \\
\text { Educação Especial. } \\
\text { Curso de Capacitação: Letra e Vida e Ler e Escrever. }\end{array}$ \\
\hline 2 & Graduação em Pedagogia com cursos de curta duração na área. \\
\hline 3 & $\begin{array}{c}\text { Magistério, graduação em Pedagogia, graduação em Letras com } \\
\text { especialização em Inglês. }\end{array}$ \\
\hline 4 & Graduação e mestrado em Artes, cursando doutorado. \\
\hline 5 & $\begin{array}{c}\text { Graduação em Educação Física com cursos de ginástica artística, } \\
\text { olímpica, geral. }\end{array}$ \\
\hline 6 & $\begin{array}{c}\text { Magistério, Graduação em Educação Física e cursos } \\
\text { complementares na área, Libras e Especialização em docência do } \\
\text { ensino superior }\end{array}$ \\
\hline 7 & Magistério, graduação em Pedagogia, pós-graduação em didática \\
\hline 8 & $\begin{array}{c}\text { Magistério, graduação em Pedagogia, pós-graduação em } \\
\text { supervisão }\end{array}$ \\
\hline 9 & Graduação em Letras \\
\hline 10 & Graduação em Pedagogia \\
\hline
\end{tabular}

Fonte: Elaborado pelas autoras com base nos dados da pesquisa.

Os relatos evidenciaram que essa formação representa apenas o início do caminho da docência e que a formação continuada torna-se importante, sobretudo quando se almeja uma educação de qualidade. Coelho (2002), ao discutir a importância da formação continuada, enfatizou a polivalência do docente que atua nos anos iniciais. A graduação em Pedagogia para os profissionais que atuam nos anos iniciais do Ensino Fundamental (EF) denotou um aspecto relevante ao trabalho das oficinas curriculares por se basear na ideia da polivalência. Embora haja diferenças entre o trabalho desenvolvido no turno regular e aquele realizado nas oficinas, as duas dimensões exigem um olhar 
polivalente sobre o educando.

O relato do sujeito 3 demonstrou, em termos práticos, esse olhar sobre o educando e as estratégias de trabalho possíveis:

Na minha opinião o único profissional capacitado para ministrar uma aula é o pedagogo porque a formação do pedagogo é completa. Ele aprende a alfabetizar, ele aprende a fazer plano de curso, plano de aula, ele aprende a trabalhar com toda, qualquer faixa etária. Ele não está preparado só para trabalhar de $1^{\mathrm{a}}$ a $4^{\mathrm{a}}$ série. (Sujeito 3)

O trecho a seguir nos permitiu refletir sobre a formação docente numa perspectiva que considera as condições de vida, a história e os elementos culturais como potenciais formativos:

Quando somamos àquelas reflexões o já citado componente ensino fundamental, nossa responsabilidade aumenta, na medida em que, nesse nível, o professor deve ser multidisciplinar, multipedagógico, multicultural, enfim... No entanto esquecemos, comumente, de nos perguntar de que forma esse profissional pode atualizar essas suas multitarefas; quais condições de trabalho possibilitam sua reflexão sobre essa prática plural; que condições epistemológicas, político- pedagógicas e financeiras lhe permitirão aprofundar sua bagagem inicial de conhecimentos, saberes e práticas. (COELHO, 2002, p. 134, grifos da autora)

Outro ponto destacado por Coelho (2002) foi a importância da legislação como instrumento político de legitimação da formação continuada como caminho para a reflexão constante da prática docente. Coelho (2002) afirmou que, como está previsto na Lei de Diretrizes e Bases (LDB), aos sistemas de ensino cabe promover a valorização dos profissionais, assegurando-lhes os termos dos estatutos e os planos de carreira. Com efeito, o ingresso no magistério público deveria ocorrer mediante concurso público e o aperfeiçoamento continuado poderia prever licença remunerada.

Entendemos, a partir das respostas dos entrevistados, que sua condição funcional mediante contratação temporária e processo outro que não concurso público não confere a esses professores os mesmos direitos daqueles que atuam no turno regular. Com isso, a incerteza de continuidade no exercício da função e a remuneração inferior, entre 
outros fatores, acabam gerando uma desvalorização profissional.

Ao indagarmos sobre a importância de uma formação específica para profissionais de ETIs, os sujeitos demonstraram acreditar mais na disposição para atuar junto aos educandos de maneira ampla, considerando-se aspectos afetivos, psicológicos além dos cognitivos, do que num curso que abordasse questões próprias desse tipo de instituição escolar.

Se eu considero importante? [Uma formação específica] Menina, sabe que você me pegou? [Expressando não ter pensado nisso antes] Mas na verdade eu até falo que são os mesmos profissionais. É a mesma formação e só que, é aquilo que eu acabei de falar, a pessoa tem que gostar, ela tem que mudar, ela tem que transformar, porque é o período integral, é mudança. Eu acho que na verdade teria que ter capacitações. Seria uma formação diferente. Ele está preparado pra trabalhar diversificado? Porque a proposta é essa: trabalhar diversificado, mas a gente sabe que não acontece, infelizmente. (Sujeito 2)

Percebemos que, para o Sujeito 2, a formação do docente dos anos iniciais, independentemente de atuar no turno regular ou nas oficinas, perpassa por questões didáticas e de metodologia. A concepção desse sujeito corrobora um ensino distinto daquele oferecido por uma escola de tempo parcial, cujas práticas se supõem distintas.

$\mathrm{O}$ PG da Escola A também se referiu às implicações que o perfil docente pode ter na qualidade do ensino da ETI, afirmando que a escola deve proporcionar a formação continuada dos educadores, por meio de estudos referentes à educação, legislações e outras literaturas nos horários pedagógicos. Castro e Faria (2002), ao analisarem a proposta pedagógica de ETIs no estado do Rio de Janeiro, afirmaram que essas instituições exigem do educador mais do que a capacidade de planejar e definir estratégias de trabalho eficazes. Para esses autores, o trabalho nessas escolas requer ousadia, preparo e perseverança diante das críticas. Assim, sugeriram que uma estratégia para a consolidação desse tipo de projeto seria o estreitamento de relações entre tais escolas e o meio acadêmico, numa parceria efetiva, mormente no que se refere à capacitação dos profissionais em benefício da qualidade educativa.

Coelho (2002) argumentou que uma escola que funcione em tempo integral não pode ser reconhecida apenas pela dupla jornada e não deve 
se pautar na repetição de tarefas e metodologias. O tempo integral deve estar atrelado à formação integral, de modo que todas as suas dimensões sejam enaltecidas por meio de atividades que incluam esporte, cultura, trabalho, artes e que ocorram por meio de metodologias diversas, ocupando todos os espaços escolares existentes no ambiente da escola.

Arroyo (2012) apontou para o risco que as escolas que se inserem em programas de ampliação de jornada correm por oferecerem mais tempo do mesmo tipo de educação. Para o autor, isso corresponderia à perda do significado político de que as ETIs deveriam se imbuir.

$\mathrm{O}$ autor salientou que, quando o ensino tradicional é imposto às camadas populares, tende a negar-lhes os direitos, por meio de atitudes antipedagógicas, antiéticas, antididáticas. Essas atitudes não seriam condizentes a uma proposta de ETI. As argumentações de Arroyo (2012) nos permitiram entender que a visão persistente na escola e na gestão do sistema escolar em relação à infância e à adolescência popular se originou de concepções preconceituosas que focaram os fracassos educacionais das camadas populares como consequência das carências mentais, materiais, familiares, que poderiam vulnerabilizar social e mentalmente as crianças e os adolescentes.

Ao relacionarmos as afirmações de Arroyo (2012) àquelas do sujeito 2, compreendemos que o trabalho pedagógico da ETI, se realizado da mesma maneira que o ensino tradicional, estaria reproduzindo um modelo de escola que sabidamente não tem produzido bons resultados junto às camadas populares. Paradoxalmente, a atuação do professor e a formação docente podem assumir importância, transformando modos de ensinar em prol das necessidades reais dos destinatários da educação.

Ao responder pergunta sobre os aspectos que considera importantes para garantia da qualidade educativa, o sujeito 3 revelou que a formação docente e o papel do professor são atributos essenciais. Note-se:

Qualidade educativa? Ah, eu acho que o crescimento do professor e busca de conhecimento. Crescimento do professor e busca de conhecimento. Como, por exemplo, de formação mesmo. Eu fiquei um tempo dando aula de inglês. Só que eu precisava de mais. $\mathrm{Na}$ minha idade, eu tenho uma visão de ensino, já passei por vários processos, mas eu tenho uma visão de ensino e eu sei que hoje eu não vou ter mais aquele aluno quietinho, sentado, parado, estático. 
Então, eu tenho essa necessidade de entrar em contato sempre com pessoas mais jovens do que eu, no caso, para poder me ensinar. Porque se for para eu levar com era antigamente, provavelmente não teria como. Porque às vezes a gente impõe determinadas coisas e depois não dá certo. (Sujeito 3)

O relato nos permitiu pensar sobre a formação continuada como forma do docente atualizar-se e trocar experiências com outros profissionais em benefício da qualidade do ensino. Outro trecho da entrevista do sujeito 3 os permitiu constatar a importância atribuída aos cursos de formação quando são específicos à necessidade do professor no domínio de conteúdos por ele trabalhados e que não foram garantidos pela formação inicial.

Fazia sete anos que eu estava fora [sem trabalhar]. Então, a gente pegou livros e tal, foi olhando para ver o que dava pra fazer o que não dava. Mas depois eu falei imagina, o que eu estou fazendo aqui? Não é isso que eu quero. Eu quero mais. É uma pena que eu não tenho domínio, [referindo-se à fluência na língua inglesa] mas eu acho que o aluno tem que saber conversar, ele tem que saber falar, pelo menos o mercado de trabalho pede a fala, pede a comunicação oral e é o que não acontece dentro da escola. (Sujeito 3)

O fato de concluir a graduação não assegura totalmente o professor em seu fazer. É por meio de sua inserção no ambiente de trabalho, de novos cursos, de trocas de experiências que ocorre um aprimoramento profissional pautado, de acordo com o relato acima, na reflexão sobre sua ação.

No caso das ETIs, a necessidade de um trabalho diferenciado nas oficinas exige que os profissionais se aperfeiçoem, o que se confirmou nos relatos a seguir.

[...] O professor a priori tem que saber o que e para quem está ensinando. A bagagem de conhecimento que traz deve ser reelaborada a cada ano ajustando-se às condições socais, ao progresso, e às próprias evoluções dos seres humanos. Dez anos atrás, o perfil das crianças não era o mesmo das crianças de hoje. [...] professores são formados de uma maneira genérica dentro de sua área. Com algumas exceções de colegas que se aperfeiçoam e se especializam, alguns acabam saindo da proposta de oficina justamente por não ter habilidade, e por fim ensinam os mesmos conteúdos de artes da grade curricular do ensino fundamental. (Sujeito 4) 
Os trechos reforçaram a importância da formação docente em virtude da necessidade de reflexão e aprimoramento do fazer pedagógico em benefício dos alunos e da equipe. Com efeito, há necessidade de um tempo destinado para isso, na jornada do professor, pois "não há possibilidade de compromisso efetivo quando o profissional não dispõe de períodos para refletir sobre seu próprio cotidiano de trabalho, principalmente quando essa tarefa envolve a formação de seres humanos" (COELHO, 2002, p. 141).

De acordo com as contribuições da autora, a extensão do tempo na mesma escola pode proporcionar aos profissionais a reflexão necessária sobre aquela prática, constituindo seu ethos como articulador das atividades educativas num determinado ambiente de trabalho, podendo ser extensivas a outros.

Monteiro (2002) destacou a necessidade e relevância dos profissionais desenvolverem pesquisas sobre a própria prática. Assim, os saberes dos professores, construídos em momentos de reflexão, possibilitam o desenvolvimento da autonomia profissional transformando as ações e relações, num processo democrático adequado à escola pública de maneira geral e, em especial, à ETI.

Mediante indagação sobre a formação docente e implicações na prática e se o profissional considerava relevante uma formação específica para professores de ETI, os entrevistados da Escola B demonstraram sua crença na formação como aspecto promotor da qualidade de ensino. Diante do nosso questionamento sobre aspectos considerados pelos profissionais como promotores da qualidade educativa, a formação apareceu como um dos elementos-chave.

A importância atribuída ao curso de Pedagogia, como um facilitador da qualidade educativa, foi percebida no relato:

Porque não têm o perfil, não tem pedagogia. $O$ primeiro passo é... Isso daí põe aí! O primeiro passo pra trabalhar na escola de período integral de 1a a 4a série é ter pedagogia, né? Isso. Por quê? Porque de 1a a 4a é mais difícil, porque teve um ano aqui que entrou professor que falou assim, o professor eu lembro... ele era de matemática... "Eu vou lavar a rua, mas não venho trabalhar aqui." Entendeu? Por quê? Porque não tem perfil, entendeu? Não é que não é capaz, não tem o perfil voltado pra 1a a 4a série. (Sujeito 10) 
Para o sujeito 8, o significado atribuído a questões que envolvem o fazer pedagógico como resultante de uma formação histórica e não só acadêmica foi reverenciado no trecho:

$\mathrm{Eu}$ acredito que eles estavam pensando em professores competentes, criativos... [Ao mencionar o tipo de profissionais considerados adequados para atuarem nas ETIs, por parte dos órgãos competentes] pra essas oficinas. Você tem que saber! Você tem que saber brincar de roda, tem que saber fazer um resgate da cultura, de joguinhos, aqueles [as] cinco marias que as crianças não sabem mais. Amarelinha, elástico, as brincadeiras que nós brincávamos. Eles [os alunos] são muito pequenos. Eu acho que tá queimando uma etapa muito importante. Que a gente tem muito menos tempo criança do que adulto. O lúdico e a brincadeira que as crianças tem que ter, esse resgate de jogos, brincadeiras, cantigas, acaba ficando pra trás. Até a família acaba descuidando e não fazendo. (Sujeito 8)

E acrescentou, diante da indagação sobre a possível interferência da formação na prática do professor:

A menos que ele seja bem criativo sem ter feito curso nenhum ou se ela é mãe e aprendeu a brincar com os filhos. Então, ela vai brincar com as crianças da mesma forma. Pelo jeito que ela brinca com o filho em casa, ela brinca com aluno também, mas a gente não tem. Tem professor que não sabe brincar com aluno. Não tem a hora de brincar. A gente pode brincar de cabra cega, de mamãe da rua, pega-pega, pega corrente. Então, acaba não passando pras crianças a nossa cultura, o nosso folclore. (Sujeito 8)

Numa outra perspectiva analítica acerca da formação docente, percebemos que os sujeitos demonstraram um sentimento de perda da valorização profissional em consequência da suspensão de cursos oferecidos pelos órgãos competentes à época da implementação do Projeto. Ficou evidente a relação que os sujeitos estabeleceram entre a valorização profissional e a oferta de cursos, principalmente porque esses sujeitos inicialmente tiveram acesso a esses cursos como uma conquista que, posteriormente, foi interrompida.

[...] eu acho que precisa mais cursos, né, pra gente. Quando eu comecei aqui a gente fazia muito curso. A gente ia pra São Paulo. Fui uma vez pra São Paulo. Então, a gente teve bastante esses cursos. Teve duas vezes que eu fui pra São Paulo, fiquei dois dias 
num hotel lá. Na verdade são quatro dias, mas eles davam esses dois dias pra fazer, a gente ficava aqui que era contagem de ponto, né? [...] Tinha, tinha substituto tá. [Para permanecer na escola enquanto os profissionais estivessem em formação] (Sujeito 10)

Outro revelou:

No início [Quando da implementação do Programa da ETI] nós tínhamos uma vez por mês uma formação. Nós tínhamos capacitação pra cada oficina, junto com a ATP. Nós tínhamos que passar como estávamos trabalhando, ela retomava, ela dava proposta, nós levávamos portfólio, apresentávamos foto do trabalho, tudo isso. E quem estava com dificuldade de trabalhar nessa oficina, já tinha assim uma luz: "Ah, então pode ser isso?" Então, era uma troca de experiência muito legal. Hoje, eles não oferecem mais, quer dizer, quem chegar hoje, dá o que quer, sabe? (Sujeito 7)

A aprendizagem do fazer docente, para além do espaço da sala de aula ou da oficina, possibilitou a troca de experiências, o convívio, a integração, as reflexões sobre questões didáticas, mas não somente. Inferimos que os momentos de formação representaram também oportunidade de conhecer espaços, lugares e elementos culturais que compõem o saber docente, além de ampliar questões técnicas intrínsecas ao trabalho pedagógico. Note-se outro trecho que enfatizou a formação/ capacitação como extremamente relevantes para o trabalho nas oficinas:

Olha é um conjunto, né, de fatores: profissionais capacitados, né, o que que são esses capacitados? Com essas ATPs, fazendo mensalmente uma capacitação, orientando, porque a coordenadora é pouco pra nós, entendeu? Somos quantos professores aqui pra uma coordenadora? É difícil, entendeu? Então, eu acho que isso é primordial. (Sujeito 10)

Almeida (2004) destacou que o desenvolvimento do profissional da educação deveria ser ponto fundamental para as políticas educacionais. Para a autora, esses aspectos estão articulados e repercutem diretamente na qualidade educativa. A partir de suas contribuições, entendemos que o professor e seu trabalho devem ser refletidos. A centralidade da formação e atuação docente, na visão da autora, foi uma ideia consonante com as expectativas dos profissionais entrevistados. Entretanto, Almeida (2004) destacou que isso só teria impacto se toda a sociedade entendesse a formação docente como aspecto preponderante da qualidade e ressaltou 
que, com as novas demandas do mundo contemporâneo, ocorreu um aumento nas atribuições do professor, sem que ocorressem mudanças em sua formação. Assim, haveria necessidade de uma nova configuração da profissão para atender às novas exigências sociais.

Outros depoimentos revelaram a compreensão dos sujeitos sobre a formação profissional como tal ausência pode repercutir no ideário desses educadores.

Acho que falta muita capacitação pra gente. Tinha que ter mais. Não, eu não peguei a época [de oferecimento de capacitações, no início do Projeto]. Eu já cheguei a fazer capacitação, mas não foi assim diretamente voltado à escola de tempo integral. Então... jogos paraolímpicos, mas eu fiz fora do horário, fiz porque eu quis acrescentar. Libras, eu fiz dois módulos. Eu tenho bastante capacitação, não só pelo estado. [...] Eu acho assim, lógico que a gente tem sempre boa vontade, os professores aqui todos têm. A gente procura fazer o melhor possível, mas acho que se tivesse uma capacitação, sabe? Alguém pra ensinar mesmo, pra abrir o leque, né? Dos nossos horizontes, seria interessante porque se pudesse sempre, todo ano ter aquela equipe, sem mudanças. Nossa, seria bem melhor, sem sombra de dúvida, porque o conhecimento nunca é demais. Às vezes você acha que faz uma atividade lá há anos. De repente você vai numa outra escola, vai numa capacitação que seja, vai fazer um curso, uma coisa que é tão simples e você fala: “Nossa! Dá pra fazer tanta coisa em cima daquilo." (Sujeito 6)

Monteiro (2002) comentou sobre as mudanças no campo da formação de professores e destacou que a concepção baseada na racionalidade técnica, em decorrência da modernidade, tem aberto caminhos a um novo modelo de formação concebida como processo contínuo. Portanto, a perspectiva assumida pela autora em muito se diferencia do enfoque normativo calcado na reprodução de saberes técnicos, normas e valores, que se completam em si mesmos.

As transformações sociais em ritmo avassalador, mormente nos grandes centros urbanos, causaram impactos nas diversas instâncias e, consequentemente, surgimento de problemas educacionais. Assim,

a formação teve, então, sua terminalidade redefinida, passando a ser concebida como um processo contínuo, podendo e devendo ser ampliada e aprofundada em vários momentos da vida dos profissionais, de forma a dotá-los de instrumental para lidar com os 
novos desafios que se apresentem, sejam eles oriundos das mudanças tecnológicas ou socioculturais. A formação, que era oferecida até então, passou a ser considerada inicial, tendência esta que tem sido observada nas diversas áreas profissionais. [...] De acordo com esse modelo, ao professor cabe adquirir os saberes e instrumentos de ação, oriundos da investigação científica realizada por outros profissionais, para serem utilizados em momento oportuno. Nesse sentido, sua ação se resumiria, basicamente, em analisar as situações para identificar quais os melhores recursos e conhecimentos de acordo com os fins que devem atingir e que, também, na maioria das vezes, já estão previamente determinados por outros. Reduzida a mera instrumentalização, essa concepção obriga o professor a aceitar a definição externa dos objetivos e métodos de sua intervenção, redundando numa verdadeira alienação de sua autonomia profissional. (MONTEIRO, 2002, p. 149- 150)

Entendemos que a formação de professores deve dotá-los de recursos científico-culturais de modo a assegurar-lhes conhecimento sobre o conteúdo a ser trabalhado, além de componente psicopedagógico que o permita entender e atuar na sala de aula. Os professores entrevistados citaram que a prática exige disposição para trabalhar de maneira diversificada ou mais lúdica, relacionando os conteúdos das disciplinas regulares com os das oficinas, demonstraram a amplitude que o papel do professor e a formação docente assumem numa proposta de ETI.

Outro aspecto considerado pelos entrevistados como determinante da qualidade educativa foi a integração entre a equipe de profissionais. A partir do referencial teórico, entendemos que a dificuldade de integração dos profissionais foi apontada como rotina das instituições públicas de ensino, paradoxalmente às revelações de sua importância como garantia da qualidade educativa (PARO, 2000, 2007; COELHO, 2002; GANZELI, 2011; ARROYO, 2012). De acordo com os autores, a lógica inerente a essas instituições no que se refere à vida funcional dos trabalhadores desencadeou um processo de isolamento do professor em relação a seus pares, por motivos dos mais diversos: falta de importância dada à integração, concepção conteudista de ensino, competitividade entre profissionais em razão do sistema político-econômico, despreparo desses profissionais para estabelecerem e aceitarem críticas sobre o próprio trabalho e dos colegas, falta de investimento do governo na formação 
em serviço, conforme mencionado.

As escolas de modo geral, e em especial as ETIs, acabam não propiciando diálogos entre a equipe pedagógica e a comunidade, o que historicamente, foi nocivo aos propósitos de um modelo educacional pautado no princípio da democracia e da participação coletiva. Ressaltamos que a integração da comunidade escolar deveria envolver a todos os profissionais, alunos e familiares.

Os relatos dos sujeitos da Escola A explicitaram a importância atribuída a esse aspecto como propiciador da qualidade das oficinas curriculares. A integração dos profissionais na Escola A, mesmo diante dos entraves impostos pelo sistema, foi apontada como um aspecto promotor da qualidade. Note-se:

A gente tenta buscar material, tenta ter uma parceria com as professoras da manhã, fazer um intercâmbio. [...] Na verdade a gente procura trabalhar 4a série com 4a série, 30 ano com 30 ano, as áreas, as séries próximas, porque daí um vai completando o outro. Orientação entra com a pesquisa, Saúde, conscientiza, o Teatro fecha uma peça, dependendo do conteúdo. Igual teve o folclore, eu trabalhei a pesquisa, a M. pegou cantigas em inglês, trouxe para trabalhar. A N. trabalhou o teatro, montou uma peça e na oficina de Saúde e Qualidade de Vida, as brincadeiras. Então, é sempre casando uma coisa com a outra. [...] Eu acho que a comunicação é tudo. Tanto entre os professores como todos os funcionários. Se tem comunicação é a base, porque daí a gente consegue levar o resto. Não adianta um falar uma língua e outro falar outra e aí não dá. Se tem uma comunicação clara, objetiva, nós vamos... que como a gente vive seguindo, que acaba sendo eu vou seguir a metodologia daquela... não... o objetivo daquele diretor. Se aquele diretor é claro com a gente, ele vai passar pra todos os funcionários a mesma coisa, aí eu acredito que anda. [...] A gente tinha uma cabeça aqui. A cabeça levava o grupo. Então, quando a cabeça saiu, acho que ficou um pouquinho desestruturado, mas o S. continuou, manteve o grupo, tudo. (Sujeito 2)

A necessidade de uma linha norteadora comum e a mediação por parte de membro da equipe gestora também fora mencionada pelos sujeitos 3 e 5. Destaquem-se as críticas às sucessivas mudanças na equipe gestora:

Quem sabe o diretor novo, a nova diretora, a postura da pessoa mediante a escola. Não sei se [você] chegou a conhecer [a diretora anterior]. Então, a postura dela é a postura que eu acho que todo 
professor precisa: de diretor! [...] [Sem uma pessoa assim, a escola, a equipe pedagógica] Perde a linha. Perde o prumo. Um fala uma coisa e depois o outro tenta fazer a mesma coisa, mas não tem personalidade. (Sujeito 3)

Eu acho que isso aí desestabiliza. Ah, e uma coisa também, troca de professor e troca de direção no meio do ano. Eu acho isso um caos. Tanto pra escola, como para a equipe escolar e os alunos. Acho que isso tinha que ser no começo do ano e já iniciar com tudo certinho. Acho que é pra estragar o que está bom. Porque o negócio está indo bem, deu certo, por que você quer trocar? Então, aqueles que estão como diretor, mas ele estava como professor, pegou a vaga, é uma escada, um degrauzinho. Cai um, o outro cai também, um tem que voltar pra sala de aula, outro tem que voltar pra outra, voltar pra outra escola, porque daí vai derrubando todo mundo. Aqui já teve duas vezes, só esse ano. Desestrutura tudo tanto a escola como o professor. Está dando uma sequência, trabalhando uma coisa legal, conquistou os alunos, deu certo, de repente vem a pessoa que... puxa, mas eu nunca vi. (Sujeito 5)

Em relação à integração entre os profissionais, o sujeito acrescentou:

Nós aqui somos tranquilos e sossegados. E não só aqui, eu trabalho, dou aula de português em outra escola e então eu estou sempre perguntando: O que você acha? Que tal a gente fazer junto? Tem uma proposta [uma ideia] assim. A gente está sempre se integrando, sempre trocando ideia. Não tem problema não. Às vezes o HTPC tem coisas específicas para passar e tem determinadas coisas que você tem que tomar uma resolução assim, de imediato. "Pessoal, olha, ontem aconteceu isso... Tal, tal, tal... Vamos ver se dá para a gente mudar a semana que vem." Então, às vezes até na troca de aulas ou aula vaga, a gente dá um alozinho: "Ah, tive uma ideia!" (Sujeito 3)

O depoimento revelou a integração entre os profissionais tanto no Horário de Trabalho Pedagógico Coletivo (HTPC) quanto em momentos do dia a dia, em razão das necessidades. Mostrou uma disposição do próprio sujeito e dos outros para trabalhar de forma integrada, mesmo em dias em que esses momentos de trocas não estavam previstos na jornada docente. No entanto, vimos que o relato apresentou contradições no que se refere à integração entre os profissionais no trecho:

A única coisa que eu acho, na minha opinião, acho não, a única coisa que eu tenho certeza que deveria acontecer na escola de tempo integral é a inclusão do professor no corpo docente. 
Professor das oficinas, no corpo docente da escola. (Sujeito 2)

Ao afirmar que deveria ocorrer a inclusão do professor (profissional da oficina) no corpo docente da escola, o sujeito evidenciou a necessidade de reflexões no âmbito da própria unidade, pois salientou fragmentações entre os turnos em detrimento da integração desejada.

Percebemos que o depoimento do sujeito 2 em relação à diferença entre os professores dos dois turnos, nos pareceu semelhante àquela vivenciada numa outra realidade. O sujeito 5 também considerou que os profissionais da Escola A constituem um grupo socialmente unido, mas não deixou de apontar algumas dificuldades relacionadas ao trabalho integrado e à importância da equipe gestora:

Nos HTPCs a gente, dependendo do que vai ter, que nem, o dia do professor, o dia do índio, tem datas específicas, que nem festa junina, nós montamos assim: entre os professores, faz uma integração do que cada um vai apresentar ou cada um vai montar. Reúne todo mundo. O bom no tempo integral é isso. Mas aqui está certo. Tem escolas que não conseguiram ter isso. Aqui deu muito certo. Eu já trabalhei em várias escolas, tive dificuldade sim. Justamente por essa falta de cumplicidade mesmo, do professor ajudar. Se não tem algum material, buscar ou a direção, a coordenação ajudar. Aqui eu tenho isso. Eu consigo resolver. Então, a gente tem suporte da direção aqui nessa escola. [...] como os professores aqui são muito unidos, a gente desenvolve coisas diferenciadas como folclore. Trabalhamos todos juntos, fizemos oficinas e cada classe teve uma oficina diferente. Então, todas as crianças passaram por várias classes pra conhecer atividades diferenciadas. [...] o negativo é o pouco tempo [para troca de experiência]. (Sujeito 5)

Os relatos dos sujeitos da Escola A destacaram a importância da integração da equipe e nos permitiram inferir que há um compartilhamento das experiências docentes mais entre os profissionais do mesmo turno, do mesmo segmento ou por interesses comuns. A integração mais efetiva, envolvendo profissionais do turno regular, das oficinas e da própria equipe gestora, pareceu um processo em construção inicial. A esse respeito, Arroyo (2012) alertou para a dificuldade de superar os dualismos existentes.

A partir das contribuições do autor, entendemos que as ETIs necessitam se atentar para esse fato, evitando atribuir ao turno regular a 
função de trabalhar conteúdos disciplinares numa relação tradicional do trabalho docente-discente que pressupõe a transmissão de conhecimentos por meio de lições, deveres de casa, avaliações, enquanto que no turno extra assumiriam destaque outras dimensões mais lúdicas, por meio de diferentes linguagens.

A tendência à fragmentação das áreas do conhecimento, dos anos escolares, dos professores de turnos distintos não se faz coerente com uma proposta de escola em tempo integral e, a partir do que pudemos compreender, a Escola A caminha na tentativa de superar o dualismo a que se referiu Arroyo (2012). Gomes (2009) argumentou que, na busca de acertar os caminhos a serem percorridos mediante a implementação do Projeto das ETIs, gestores e professores das instituições em que a autora desenvolveu sua pesquisa encontraram formas de conceber o tempo e o espaço de que dispunham, com adequações da nova rotina de modo a evitar sobressaltos.

Na Escola B, a integração entre os profissionais também foi apontada como aspecto determinante da aprendizagem dos alunos. Esses professores consideraram os conteúdos como aspecto determinante da qualidade educativa e, em virtude disso, acabaram assumindo responsabilidades alheias aos princípios determinados nas DETIs para as oficinas curriculares. Alguns relataram priorizar o trabalho de reforço pedagógico em vez de desenvolver as atividades previstas nas DETIs em decorrência de cobranças dos órgãos centrais por resultados. $O$ fato põe em risco o cerne do Projeto ETI, pois transforma o tempo das oficinas curriculares em aulas de reforço e preparação para avaliações.

Assim, o não cumprimento das DETIs e o entendimento dos professores sobre a importância do trabalho desenvolvido no turno regular obrigou os professores das oficinas curriculares a assumirem uma prática pedagógica semelhante, o que comprometeu a qualidade educativa dessas oficinas. Contudo, ao assumir prática pedagógica voltada para o reforço dos conteúdos desenvolvidos no turno regular, os professores das oficinas conseguiram estabelecer uma maior integração com a equipe. Note-se no trecho a seguir.

Aí a gente conversa com os outros professores. Sempre estamos assim conversando. Eu sempre... Todos nós, né, todas nós, estamos 
sempre conversando com os professores da manhã pra fazer uma troca. Aí a gente trabalha assim. Então, foi o que eu te falei. [...] Nós agora, da 4a série como nós estamos trabalhando reforço é muito [grande] entendeu, minha integração com ela, com a [professora] da manhã aqui que é a N. A gente trabalha juntas mesmo, entendeu? Sempre trocando, entendeu? Tanto que ela faltou e deixou material [para a aula]. Mas a gente trabalha junto, falando a mesma língua porque é um aluno só, né? Então, com os outros [profissionais] também temos. Olha, é assim: só não tenho muito [contato] com os [professores dos] pequenininhos, entendeu, de 1 o ano. Agora, os demais sim, todos a gente sempre tá [trocando experiências] em HTPC ou plano [planejamento], reunião pedagógica. Ficam todos os professores das oficinas. Então, a gente interage, vai mostrando tudo que você tá trabalhando, vai falando, entendeu? (Sujeito 10)

A integração entre os professores, embora imbuída de intencionalidade de melhoria do trabalho desenvolvido, avaliação mais pontual dos alunos, completude entre os turnos, acabou revelando mais uma preocupação com os resultados exigidos. Percebemos que o trabalho integrado ocorreu de modo a se voltar para os problemas relacionados à aprendizagem dos alunos ou a questões organizacionais, como a falta de profissionais.

Relatos dos sujeitos revelaram que desde a implementação das ETIs houve momentos em que o trabalho integrado fora priorizado e outros em que fora esquecido. A descontinuidade do processo de construção que demanda a intencionalidade de se desenvolver um trabalho integrado, que valorizasse a reflexão coletiva e a tomada de decisões pelo grupo de profissionais, repercutiu na qualidade educativa das oficinas curriculares. Acrescentamos que isso seria prejudicial para o grupo constituído na escola desde o início da implementação e, mais ainda, para profissionais recém- chegados à escola.

Eu vou ser sincera, já foi assim muito bom! Quando nós tínhamos uma equipe que se interessava, uns professores assim bem capacitados. Hoje, com essa mudança aí na educação, com essas provinhas, o que está acontecendo? Eles [os órgãos como a DE] estão mandando, professores que nunca tiveram em sala de aula ou professores que já tiveram, mas não têm conhecimento. Não têm experiência e aí o que está acontecendo? Nós temos mais trabalhado a indisciplina dos alunos. E mesmo ter que participar junto com eles [os professores novos] na sala pra ver se eles [os 
alunos] diminuem, [a indisciplina] entendeu? Não pelo aluno, pela... falta de prática deles, [professores] mas mesmo assim as que ficaram, né. As professoras que estão desde o início, a gente tem entrosamento. Eu me entroso muito com a K. porque nós estamos desde o começo. Uma sabe o que quer passar, a outra [fala] "Vamos trabalhar isso? Ah vamos. É isso mesmo." Inclusive foi uma conversa que eu tive com a coordenadora pro ano que vem mudar isso. Que todo ano fica esperando. “Ah, fulano é novo? Vamos esperar. Não! Tem que começar uma proposta, nós vamos trabalhar isso." Elas se viram pra trabalhar isso. Encaixam, porque era muito gostosa essa interdisciplinariedade que nós fazíamos. Hoje, está cada um pra si. Então, no HTPC, é o momento que nós temos. Segunda e quarta. (Sujeito 7)

Outro sujeito revelou que a tentativa de se realizar um trabalho integrado na escola sempre foi difícil, devido ao acúmulo de cargos por parte dos professores em função da necessidade financeira e da instabilidade gerada pelas categorias instituídas pelo governo do estado para não efetivar os profissionais por meio de concurso público.

A gente... a gente, a maioria dos professores, $90 \%$ faz uma troca de experiências boa. Não, porque a gente tem os horários de HTPC. Encontra, conversa. Não, às vezes não especificamente para... como eles têm o HTPC mais cedo, eles acabam indo até a sala do professor, conversam, trocam ideias. Fica difícil porque tem professor que dobra, por exemplo, a gente tem uma meia dúzia, mais ou menos, de professor do período da manhã que trabalha à tarde. Sai daqui correndo pra almoçar ou então vai comendo um lanche no carro e já entra noutra escola. Então, é o tempo de comer alguma coisa, é o tempo de sair de uma escola e ir pra outra, engolir alguma coisa no caminho. Então, quando dá o sinal de ir embora, tem que ir embora. O certo seria uma reunião pedagógica, uma reunião pedagógica bimestral. Então, é isso que eu estava falando. Eu acho que interessante seria ter pelo menos bimestral, um encontro pedagógico, uma reunião pedagógica pra essa troca. (Sujeito 8)

Gomes (2009) também colheu relatos dos gestores das escolas investigadas em sua pesquisa acerca do acúmulo de cargos dos profissionais. A autora destacou que as condições de vida dos profissionais da educação pública os obrigam a acumular cargos na esfera estadual, municipal e particular. Depreendemos a semelhança entre o relato do Sujeito 8 de nossa pesquisa com trechos das entrevistas 
realizadas por Gomes (2009) em outras realidades:

Temos professores que nem almoçam, têm o tempo só para o deslocamento. O professor que trabalha mais de 40 horas não tem tempo de sentar para preparar algo. Eu trabalho só de manhã, quer dizer eu tenho mais tempo. Mas também não acho justo trabalhar sem remuneração, o professor teria que ter um tempo remunerado, fora da aula. (B4)

Meu desempenho do ano passado para esse ano caiu muito. Estou em três escolas, no ano passado eu só estava aqui, então nas janelas eu preparava as aulas para as oficinas. Saio às 12 horas e $13 \mathrm{~h} 20$ tenho que estar na outra escola. Depois saio às $16 \mathrm{~h} 10$ e tenho que dar aula à noite. Só com as oficinas não dá para sobreviver. (A3) (GOMES, 2009, p. 134).

A dificuldade encontrada pelos profissionais para se reunirem e discutirem sua prática também foi atribuída às determinações da DE acerca da suspensão de aulas. Conforme revelou sujeito, a seguir, o cumprimento das horas-aulas diárias foi priorizado, mas a integração da equipe necessitaria de investimento de tempo em reuniões pedagógicas.

É assim, mas não é sempre, sempre não dá. Na verdade a gente tem que cumprir aquela meta de aulas. Tem que mandar pra eles [órgãos da administração] essa quantidade de aulas o que eu acho errado porque pelo menos uma vez por mês, minha opinião, teria que ter uma reunião sem alunos. Não, eles [referindo-se à $\mathrm{DE}$ ] não deixam mesmo a diretora pedindo. Eu acho que tem que ter qualidade e não quantidade, né? Claro, ninguém vai vir aqui pra ficar um olhando pra sua cara e um olhando pra... [pro outro] A gente nem sai de casa pra isso. Tanta coisa que a gente tem pra fazer, mas eles não entendem. Eles, eu digo, os de cima. Não entendem. (Sujeito 9)

Outro fator que dificultou a integração entre os profissionais foi a existência de apenas uma professora coordenadora para atender toda a escola e acompanhar o trabalho das oficinas curriculares.

Olha é um conjunto de fatores: profissionais capacitados. O que são esses capacitados [o que quer dizer capacitados]? Com essas ATPs, fazendo mensalmente uma capacitação, orientando, porque a coordenadora é pouco pra nós, entendeu? Somos quantos professores aqui pra uma coordenadora? É difícil, entendeu? Então, eu acho que isso é primordial. Então, foi o que eu te falei. [...] Nós agora, da 4a série como nós estamos trabalhando reforço, 
é muito entendeu, minha integração com ela, com a da manhã aqui que é a N. A gente trabalha juntas mesmo, entendeu? Sempre trocando, entendeu? Tanto que ela faltou e deixou material. Mas a gente trabalha juntas, falando a mesma língua. Então, com os outros [professores] também temos. Olha, é assim só não tenho muito com os [professores dos] pequenininhos, entendeu, de 1 o ano. Agora, os demais sim, todos. A gente sempre tá... e em HTPC ou plano, reunião pedagógica... fica todos os professores das oficinas. Então, a gente interage, vai mostrando tudo que você tá trabalhando, vai falando, entendeu? (Sujeito 10)

O modo como a equipe gestora está constituída, com a fragmentação do administrativo e o pedagógico, demonstrou necessidade de reconfiguração, para que de fato houvesse integração do trabalho. Uma reflexão mais detida de toda a equipe pedagógica poderia representar o ponto de partida para um trabalho efetivamente integrado, sobretudo nas oficinas curriculares que representam o diferencial do paradigma em questão.

Cavaliere (2009) comentou sobre a atuação dos gestores, em especial dos diretores das escolas investigadas em sua pesquisa:

Os diretores, como responsáveis pelo sucesso da escola e os pais como responsáveis pela boa educação dos seus filhos, destacaram, cada grupo a seu modo, os aspectos positivos da escola de tempo integral, particularmente os relativos à melhoria da qualidade da educação. Os diretores, aparentemente mais por convicção do que por dever do cargo argumentaram politicamente a favor dela, lembrando as várias fases vividas e, com muito cuidado, revelando as perdas sofridas. (CAVALIERE, 2009b, p. 17)

Logo, a convicção dos gestores acerca da melhoria da qualidade da educação por meio da ETI pareceu-nos essencial para existência, manutenção e êxito dessas escolas.

\section{Considerações}

A ETI como uma perspectiva educacional mais completa e democrática ganhou destaque nos discursos políticos e acadêmicos por representar um caminho para a qualidade educativa. No entanto, vimos que a polissemia do conceito de qualidade resultou em ações isoladas e na ausência de um direcionamento teórico-filosófico comum 
aos projetos de ETI.

Entendemos, por um lado, que a implementação do Projeto ETI por um lado representou um ganho no que se referiu à necessidade de garantir o direito social à educação. Outro aspecto positivo foi o fato de permitir reflexões acerca do paradigma em questão, principalmente porque contou com a elaboração de diretrizes específicas para sua organização. Por outro lado, ao enfatizar um modelo educacional fundamentado no desenvolvimento de habilidades e competências, o projeto pareceu atrelar-se às exigências da sociedade capitalista, voltadas à preparação para o trabalho, não se comprometendo com uma formação mais ampla.

A escola de EF, sobretudo dos anos iniciais, deve ser um espaço de construção de valores por meio do trabalho com os conteúdos previstos e a partir das interações sociais. Assim, procuramos identificar e compreender as percepções dos professores das oficinas curriculares sobre a qualidade educativa, exatamente porque representaram um diferencial das ETIs em relação às demais escolas (de tempo parcial).

A partir das argumentações de Barros (2008), entendemos que a qualidade educativa deve se atrelar a uma perspectiva democrática em que esforços são empreendidos em benefício da melhoria da qualidade de vida daqueles que tiveram prejuízo de direitos. Logo, a qualidade educativa se vincula ao que a autora chamou de qualidade social e emancipadora, centrada na formação humana, e não na produtividade ou na qualidade total. Desse modo,

para que as instituições educacionais realizem seus trabalhos com legitimidade na sociedade, faz-se necessário que se reveja a maneira como a qualidade vem sendo tratada no âmbito escolar. Isso implica dizer que, em uma escola de tempo integral, a qualidade não tem uma dimensão mercadológica, ao contrário, aplica-se a esta escola outra noção de qualidade que está, como foi dito, referenciada em valores sociais de emancipação. Até porque a qualidade embasada em valores de mercado tem representado um acirramento da crise social. (BARROS, 2008, p. 251)

Compreendendo a ETI na perspectiva de Barros (2008) e a partir dos dados obtidos em nossa pesquisa, constatamos haver diferenças entre o que está previsto nos documentos e o plano da realidade. As entrevistas 
indicaram aspectos recorrentes nas falas dos professores das oficinas, o que evidenciou tais diferenças como determinantes da qualidade educativa. Os relatos dos sujeitos nos fizeram identificar aspectos por eles percebidos e que envolveram diretamente a questão da qualidade.

A partir desses relatos, percebemos que, para os professores, a qualidade educativa das oficinas curriculares está diretamente relacionada à formação docente e à integração entre a equipe. Salientamos que outros aspectos menos recorrentes também foram apontados pelos sujeitos, mas em virtude dos limites desse trabalho não foram analisados.

Algumas falas demonstraram uma compreensão de educação conformada com situações de escassez e improviso diante das adversidades, como se observou no excerto:

Eu acho que daqui eu não tenho do que reclamar. Eu gosto muito da escola, do pessoal. Já tive muitos problemas em outras escolas também por falta de material porque o material em educação física é escasso. Na educação física, você tem que ter o aparelho pra você trabalhar, o material. Se você não tem é complicado. Nos viramos quando não temos. Quando eu comecei trabalhar foi engraçado porque se eu não tivesse uma bola, alguma coisa, eu ficava num desespero: “O que eu vou fazer?" E aí você, com o tempo e com a experiência, você vai vendo que mesmo sem material você trabalha com eles. É aquele negócio: brinca com o próprio tênis, brinca com a própria roupa, você brinca com qualquer coisinha... até reciclável, mas no começo, quando a gente sai da faculdade, vem pra cá, tem uma teoria linda. Você chega aqui, dá de frente com uma coisa assim: “E agora? Que que eu vou fazer?" Não tem material, não tem isso, espaço é mínimo. Quarenta alunos pra você cuidar. Como é que você vai fazer sozinha? E assusta, né? Quando você acha que já aprendeu tudo, no outro dia você está aprendendo uma coisa nova (Sujeito 5)

Além de se acomodar diante das dificuldades cotidianas, alguns professores pareceram se responsabilizar pela situação da escola, aceitando as falhas do sistema como responsabilidade exclusiva dos docentes.

Note-se:

Então, para garantir essa qualidade falta ainda muito material. Material pra pesquisa, material pra manuseio deles. Essa ausência, às vezes complica. Às vezes falta papel. Eu acho que o próprio estado poderia ter algo assim pra nos oferecer. Como eles oferecem 
o computador, mas muito pouco usado pela própria dificuldade que nós estamos encontrando em controlar. Então, acontece de parar um e não tem assistência pra isso. Então, no começo da escola de tempo integral tinha muita coisa pra nós. A gente até sonhava, principalmente a sala de informática que a própria APM poderia contratar alguém pra vir arrumar. Estava muito bom. Com a troca do governo, o governo fez uma parceria com essa nova firma que trouxe os computadores. Nessa parceria o que ele propôs/ Que todo processo que precisasse de conserto, eles estariam disponíveis. Uma pessoa pra isso. Não aconteceu! E os que já vieram, eu acho que não tinham uma formação completa pra isso e em vez de deixar arrumado, alguns [computadores] pioraram. Não adiantou nada. Tinha dez computadores funcionando, eles saíram daí ficaram seis. (Sujeito 7)

Os professores entrevistados lidam com a falta de espaço, falta de recurso humano, falta de material, falta de momentos de integração da equipe e falta de formação, o que consideramos incoerente com a expectativa do projeto sobre a pretensa qualidade. As DETIs afirmaram que a qualidade educativa depende de fatores relacionados à estrutura organizacional das escolas, além da formação docente e da concepção pedagógica, mas o contraturno das aulas confirmou uma realidade outra em que a falta de condições se sobrepõe ao desejo revelado no referido documento.

Ademais, os professores das oficinas curriculares deveriam ter a mesma valorização daqueles que atuam no turno regular. Ressalvadas as diferenças em virtude das disciplinas ou oficinas oferecidas e da situação funcional, atribuímos extrema relevância a esses agentes e às relações de ensino- aprendizagem que estabelecem. De acordo com nossas considerações, o Projeto de ETI no estado de São Paulo deveria se atrelar efetivamente às necessidades das camadas populares e ao direito à qualidade educativa, reconhecendo-se a importância do educador nesse processo. A educação não pode transformar a sociedade, contudo, sua contribuição para o processo de desenvolvimento humano é inegável.

Em consonância com as argumentações de Paro (2007), defendemos a necessidade de uma reflexão crítica e da ressignificação do conceito de qualidade de modo que sirva de horizonte e parâmetro para a proposição de políticas públicas consistentes e realistas para o ensino fundamental, com destaque para as ETI. 


\section{Referências}

ALMEIDA, M. I. Docentes para uma educação de qualidade: uma questão de desenvolvimento profissional. Educar em Revista, Curitiba, n. 24, p. 165-176, 2004. Disponível em: <http://goo.gl/ g6z5qT>. Acesso em: 01 dez. 2012.

ARROYO, M. G. O direito a tempos-espaços de um justo e digno viver. In: MOLL, Jaqueline et al. (Orgs.). Caminhos da educação integral no Brasil: direito a outros tempos e espaços educativos. Porto Alegre: Penso, 2012. p. 33-45.

BARROS, K. O. A escola de tempo integral como política pública educacional: a experiência de Goianésia - GO (2001-2006). 2008. 189 f. Dissertação (Mestrado em Educação) - Faculdade de Educação, Universidade de Brasília, Brasília. 2008. Disponível em: <http:/ / goo. gl/toqb3k>. Acesso em: 18 out. 2011.

BRASIL. Lei n ${ }^{0}$ 9.394, de 20 de dezembro de 1996. Estabelece as Diretrizes e Bases da Educação Nacional. Diário Oficial da União, Brasília, DF, 23 dez. 1996.

BRASIL. Secretaria de Educação Fundamental. Parâmetros curriculares nacionais: introdução aos parâmetros curriculares nacionais. Brasília: MEC/SEF, 1997. Disponível em: <http:/ / goo.gl/ QuPqdT>. Acesso em: 05 jan. 2012.

CASTRO, A. R. V.; FARIA, L. C. M. CIEP - o resgate da utopia. In: COELHO, L. M. C. C.; CAVALIERE, A. M. V. (Org.). Educação brasileira e(m) tempo integral. Rio de Janeiro: Vozes, 2002. p. 83-92.

CAVALIERE, A. M. As escolas de horário integral segundo seus diferentes atores. In: CONGRESSO BRASILEIRO DE SOCIOLOGIA, 14., 2009, Rio de Janeiro. Anais... Rio de Janeiro: UFRJ, 2009. 
COELHO, L. M. C. C. Formação continuada do professor e tempo integral: uma parceria estratégica na construção da educação integral. In: COELHO, L. M. C. C.; CAVALIERE, A. M. V. (Org.). Educação brasileira e (m) tempo integral. Rio de Janeiro: Vozes, 2002. p. 133-146.

GANZELI, P. (Org.) Reinventando a escola pública por nós mesmos. Campinas, São Paulo: Alínea, 2011.

GOMES, M. C. L. Escola de tempo integral: redimensionar o tempo ou a educação? 2009. 165 f. Dissertação (Mestrado) - Faculdade de Educação, Pontifícia Universidade Católica de Campinas, Campinas, 2009.

LUDKE, M.; ANDRÉ, M. Pesquisa em educação: abordagens qualitativas. São Paulo: EPU, 1986.

MONTEIRO, A. M. A formação de professores nos CIEPs: a experiência do curso de atualização de professores para escolas de horário integral no estado do Rio de Janeiro de 1991 a 1994. In: COELHO, L. M. C. C.; CAVALIERE, A. M. V. (Org.). Educação brasileira e (m) tempo integral. Rio de Janeiro: Vozes, 2002. p. 147-167.

PARO, V. H. Gestão democrática da escola pública. São Paulo: Ática, 2000.

PARO, V. H. Gestão escolar, democracia e qualidade do ensino. São Paulo: Ática, 2007. 